\title{
Trends of socioeconomic inequality in using maternal health care services in Lao People's Democratic Republic from year 2000 to 2012
}

\author{
Ngan Do ${ }^{1}$, Huong Thi Giang Tran², Alay Phonvisay ${ }^{3}$ and Juhwan Oh ${ }^{1 *}$ (D)
}

\begin{abstract}
Background: Socioeconomic inequalities in access to maternal health care have received more attention as it challenges the sustainability of the ongoing achievement in reducing maternal mortality. By promoting access to maternal health care as one of the core targets of the Health Sector Reform, Lao People's Democratic Republic has reduced maternal mortality dramatically over the last decade. In spite of this improvement, little has been known about the secular trends in disparities of service utilization across different socioeconomic subgroups.

Methods: Two waves of the Multiple Indicator Cluster Survey in the years 2000 and 2012 were pooled for the analysis. We used logistic regression to estimate the likelihood of using antenatal care (ANC) and delivery services with skilled birth attendants (SBA) across different socioeconomic subgroups. Difference-in-difference method was applied to examine the inequality trends across the years by analyzing the interaction terms of the survey years and socioeconomic factors (education, wealth, ethnicity, and residential areas).

Results: Urban-rural disparity was improved over time while there were no educational disparity changes. Rural residential areas showed significant changes than urban areas over time [OR $=2.40 ; 95 \% \mathrm{Cl}: 1.52-3.77$ for ANC and $\mathrm{OR}=2.16$; $95 \% \mathrm{Cl}: 1.36-3.42$ for SBA]. However, there were aggravations in the disparities between major and minor ethnic group as well as worsening disparities between the rich and poor: i.e. Ethnic minority showed significant aggravation over time [OR $=0.62 ; 95 \% \mathrm{Cl}: 0.44-0.89$ for ANC and $\mathrm{OR}=0.65 ; 95 \% \mathrm{Cl}: 0.44-0.97$ for SBA]

Conclusions: Efforts to increase maternal health service utilization in poor and minority ethnic groups should be emphasized to reduce social inequalities, thus encompassing multiple-sector interventions rather than focusing only on health sector related interventions.
\end{abstract}

Keywords: Trends, Inequality, Socioeconomic factors, Maternal health services, Lao People's Democratic Republic

\section{Background}

Maternal mortality remains a major global public health issue, especially in low-middle income countries, despite significant achievements. Between the year 1990 and 2008 , the maternal death reduced $34 \%$ (from 546,000 to $358,000)$ and the maternal mortality ratio also declined $34 \%$ (from 400 to 260 maternal deaths per 100,000 live births) worldwide [1]. Regardless of this, disparities

\footnotetext{
*Correspondence: oh328@snu.ac.kr

'JW Lee Center for Global Medicine, Seoul National University College of Medicine, 71 Ihwajang-gil, Jongno-gu, Seoul 13087, Republic of Korea Full list of author information is available at the end of the article
}

across countries in reducing maternal mortality is high [2-4]. Sub-Saharan Africa and South Asia are the two regions accounting for $85 \%$ of maternal mortality globally [5]. Inequalities in accessing to maternal health care services, quality of care, and social determinants (including education, place of residence, and wealth) are key drivers of the trend $[6,7]$. Within countries, women of disadvantaged socioeconomic groups tend to have less access to maternal health care services, receive low quality services, and die from childbirth related causes [8-13]. Furthermore, inequalities challenge the progress of reducing maternal mortality $[14,15]$. For example, in Namibia

(c) The Author(s). 2018 Open Access This article is distributed under the terms of the Creative Commons Attribution 4.0 International License (http://creativecommons.org/licenses/by/4.0/), which permits unrestricted use, distribution, and 
sub-national inequality is one of the main reasons the decreasing maternal mortality trend reversed, with the maternal death rate increasing from 271 (between 1991 and 2000) to 499 deaths per 100,00 live births (between 1998 and 2007) [16].

Lao People's Democratic Republic (Lao PDR) is one of the ten "fast-track" countries, including Bangladesh, Cambodia, China, Egypt, Ethiopia, Nepal, Peru, Rwanda, and Vietnam, who are doing better than comparable countries in reducing maternal mortality [17]. Maternal mortality ratio has decreased substantially in the last decade, from 1100 (in 1990) to 220 (in 2012) per 100,000 live births [18]. The government has put maternal health care services as the entry point to strengthen the healthcare system in the Health Sector Reform agenda [19]. Various programs have been implemented, including comprehensive health system strengthening interventions in Northern provinces and free deliveries for the poor in Southern provinces. However, research on inequalities of maternal health service utilization among socioeconomic groups in Lao PDR is surprisingly limited. Inadequate research and data pose to significantly challenge addressing the sustainability of the achievements in reducing maternal mortality in the country. Although the differences in the use of maternal services among socioeconomic groups can be found in reports of the government or development partners, the information is given in a very crude level without controlling for other factors.

This paper aims to examine the differences in using maternal health care services across different socioeconomic subgroups in Lao PDR. It also presents the changes in the service utilization patterns and equality trends from year 2000 to 2012.

\section{Methods}

\section{Data and variables}

From the 2000 and 2012, two rounds of the Lao PDR Multiple Indicator Cluster Surveys (MICS) were carried out by the Ministry of Planning and Investment (National Statistical Center) and the Ministry of Health (National Institute of Public Health) with the support of the United Nations International Children's Emergency Fund (UNICEF). The data was collected using the standard MICS questionnaires and techniques. Eligible participants were defined as women aged 15-49 living as usual residents of the household. They were interviewed with a questionnaire, which consisted of seven parts. Maternal and newborn health was one of sections with more than 20 questions reporting the health care experience of the mother and the newborns. This current study focused on the maternal health care related questions to analyze maternal health care service utilization between the two survey rounds.
The Additional file 1: Table S1 describes the variables. The use of maternal health care services was examined by two outcome variables: Antenatal Care Visit (ANC) and delivery with a Skilled Birth Attendant (SBA). The use of ANC was counted when the women had at least one visit to health professionals during pregnancy. The use of SBA was defined as the delivery experience with a health professional such as a doctor, nurse, midwifed or auxiliary midwife. Traditional birth attendants and community health workers were not considered as health professionals. The socioeconomic equity indicators used in this study were: ethnicity, residential area (urban vs. rural), educational level, and household wealth. Other covariates included mothers' age and access to media.

\section{Analysis}

We used binary logistic regression to analyze the relationship between outcome variables and socioeconomic factors. The logistic regression Odds Ratios (OR) represents the likelihood of using ANC and delivery by a SBA in each socioeconomic category. It indicates the degree of socioeconomic inequality in utilizing ANC and a SBA of the socioeconomic groups compared to the referenced group. The logistic regression was run on the pooled data of the two rounds of MICS, which allowed us to use the difference-in-difference model to estimate the secular trend. We put two-way interactions between the survey year and the socioeconomic variables (the educational level of the woman, ethnicity, residential area, and household wealth) into the logistic model after adjusting for the mother's age and exposure to media. The interaction terms helped avoid bias and misinterpretation of the different effects of socioeconomic factors on maternal health care service utilization over time [20-22]. If the interaction between one of socioeconomic variable and survey years was non-significant, the relationship of the outcome variable and the socioeconomic independent variable could be interpreted consistent over time: In other words, there were no changes in the inequality in that independent variable over time. If the interaction term was significant, it should be considered as a change in inequality. In that case, we further present the interaction effects by plotting the interaction into graphs for visual depiction.

\section{Results}

Table 1 summarizes the characteristics of the study sample. More than half of the women in this study were non-Lao. Most of them were in their 20s $(53.79 \%$ in 2000 and $58.44 \%$ in 2012$)$ and 30 s $(28.79 \%$ in 2000 and $24.46 \%$ in 2012). Forty-five percent of women reported no education in 2000, which was reduced to $30.67 \%$ in 2012 . The number of women who ever attended schools increased between 2000 and 2012. Eighty-four percent of women in 2000 reported access to media (radio, newspaper, or 
Table 1 Description of the study sample

\begin{tabular}{|c|c|c|}
\hline Year & 2000 & 2012 \\
\hline Number of women in the study sample & $1161(100.00 \%)$ & $4444(100.00 \%)$ \\
\hline Number of women used antenatal services at least one time & $337(29.05 \%)$ & $2309(51.96 \%)$ \\
\hline Number of women delivered with health professionals & $246(21.23 \%)$ & $1705(38.36 \%)$ \\
\hline \multicolumn{3}{|l|}{ Ethnicity of household head } \\
\hline Lao & $510(43.97 \%)$ & $1778(40.02 \%)$ \\
\hline Non-Lao & $651(56.03 \%)$ & $2666(59.98 \%)$ \\
\hline \multicolumn{3}{|l|}{ Mother's age } \\
\hline $15-19$ & $138(11.90 \%)$ & $580(13.05 \%)$ \\
\hline $20-29$ & $625(53.79 \%)$ & $2597(58.44 \%)$ \\
\hline $30-39$ & $334(28.79 \%)$ & $1087(24.46 \%)$ \\
\hline $40-49$ & $64(5.52 \%)$ & $180(4.05 \%)$ \\
\hline \multicolumn{3}{|l|}{ Mother's education } \\
\hline None & $526(45.27 \%)$ & $1363(30.67 \%)$ \\
\hline Primary & $451(38.86 \%)$ & 1855 (41.74\%) \\
\hline Secondary and higher & $184(15.87 \%)$ & $1226(27.59 \%)$ \\
\hline \multicolumn{3}{|l|}{ Access to media (radio, newspaper, TV) } \\
\hline Yes & $975(84.01 \%)$ & $3364(75.70 \%)$ \\
\hline No & $186(15.99 \%)$ & $1080(24.30 \%)$ \\
\hline \multicolumn{3}{|l|}{ Residential area } \\
\hline Urban & $218(18.79 \%)$ & $890(20.03 \%)$ \\
\hline Rural & $943(81.21 \%)$ & 3554 (79.97\%) \\
\hline \multicolumn{3}{|l|}{$\mathrm{HH}$ wealth index quintile } \\
\hline Poorest quintile & $313(26.98 \%)$ & $1367(30.76 \%)$ \\
\hline Second quintile & $247(21.30 \%)$ & $1010(22.73 \%)$ \\
\hline Third quintile & $210(18.10 \%)$ & $848(19.08 \%)$ \\
\hline Fourth quintile & $203(17.50 \%)$ & $668(15.03 \%)$ \\
\hline Richest quintile & 187 (16.12\%) & 551 (12.40\%) \\
\hline
\end{tabular}

television) and in 2012 the number was $75.70 \%$. Eighty one per cent of women were living in rural areas in 2000 which was reduced by $1.24 \%$ in 2012 . The utilization of ANC and SBAs doubled between the years 2000 and 2012. Twenty-nine percent of the respondents reported accessing to ANC in 2000, in 2012 increased to $51.96 \%$. The rate of delivery with a SBA also increased from $21.23 \%$ in 2000 to $38.36 \%$ in 2012 .

Table 2 presents the differences in maternal health care service utilization across different socioeconomic groups. Women living in households headed by non-Lao ethnics were less likely to use both $\mathrm{ANC}[\mathrm{OR}=0.56$; 95\% CI: 0.47-0.66] and SBA [OR $=0.71$; 95\% CI: 0.590.85]. Compared to the mothers who had never attended school, the mothers who had attended primary school were more likely to use ANC [OR $=2.32$; 95\% CI: $1.97-$ 2.74] and more likely delivery with a SBA $[\mathrm{OR}=1.40$; 95\% CI: 1.12-1.70]. Women with secondary or higher education were more likely to use ANC $[\mathrm{OR}=4.58$; $95 \%$
CI: 3.70-5.68] and more likely to use a SBA [OR $=3.71$; 95\% CI: 2.96-4.65]. There were statistically significant differences in the service use across residential areas. The women living in rural areas were less likely to use ANC [OR $=0.36$; 95\% CI: 0.29-0.43] and a SBA [OR = 0.29; 95\% CI: 0.24-0.35]. The richest quintile women were more likely to use antenatal services $[\mathrm{OR}=3.41$; 95\% CI: $2.53-$ 4.59] and more likely to deliver with a SBA [OR $=8.21$; 95\% CI: 5.99-11.27] compared to the poorest quintile women. The likelihood of using maternal services was lower among those who had no access to media such as newspaper, radio, or television.

Table 3, Fig. 1, and Fig. 2 show secular trend of diverse socioeconomic inequalities through the interaction effects of socioeconomic factors and survey year. The interaction between educational attainment of the mothers and the survey year was not statistically significant. Statistical significance was found in the interaction terms of survey year and ethnicity $[\mathrm{OR}=0.62$; $95 \% \mathrm{CI}$ : 
Table 2 The association between socio-demographic factors and maternal health service utilization in Lao PDR (2000, 2012)

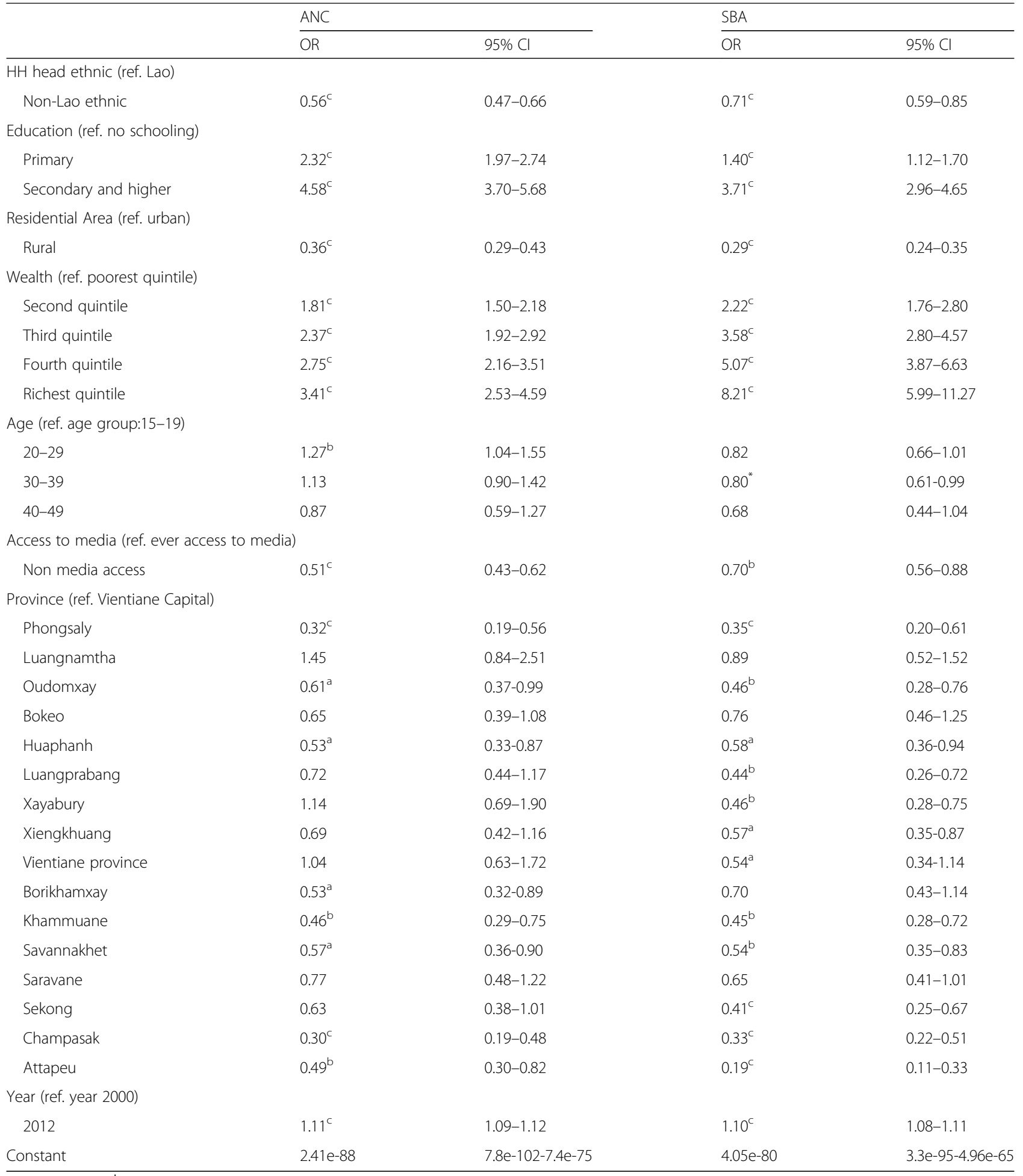

${ }^{a}: p$-value $<=0.05 ;{ }^{\mathrm{b}}: p$-value $<=0.01 ;{ }^{c}: p$-value $<=0.001$

0.44-0.89 for ANC and OR = 0.65; 95\% CI: 0.44-0.97 for SBA]. Survey year and residential areas also showed statistically significant changes $[\mathrm{OR}=2.40$; $95 \% \mathrm{CI}: 1.52-$ 3.77 for $\mathrm{ANC}$ and $\mathrm{OR}=2.16$; $95 \% \mathrm{CI}$ : $1.36-3.42$ for
SBA]. The plots in Fig. 1 and Fig. 2 showed an increase in using both ANC and a SBA. The increase in ANC and delivery by a SBA were higher among Lao ethnic woman than non-Lao, among rural residents than urban, 
Table 3 Interaction terms between socio-economic characteristics and years of survey for maternal service utilization

\begin{tabular}{|c|c|c|c|c|}
\hline & \multicolumn{2}{|l|}{ ANC } & \multicolumn{2}{|l|}{$\underline{\mathrm{SBA}}$} \\
\hline & OR & $95 \% \mathrm{Cl}$ & OR & $95 \% \mathrm{Cl}$ \\
\hline \multicolumn{5}{|c|}{ Ethnicity of household head (ref. Lao) } \\
\hline Non-Lao & $0.62^{\mathrm{b}}$ & $0.44-0.89$ & $0.65^{\mathrm{a}}$ & $0.44-0.97$ \\
\hline \multicolumn{5}{|c|}{ Mother's education (ref. no education) } \\
\hline Primary & 1.15 & $0.76-1.75$ & 1.21 & $0.75-1.95$ \\
\hline Secondary and higher & 0.68 & $0.40-1.15$ & 1.09 & $0.64-1.86$ \\
\hline \multicolumn{5}{|l|}{ Residential area (ref. urban) } \\
\hline Rural & $2.40^{c}$ & $1.52-3.77$ & $2.16^{\mathrm{b}}$ & $1.36-3.42$ \\
\hline \multicolumn{5}{|c|}{$\mathrm{HH}$ wealth index quintile (ref. the poorest quintile) } \\
\hline Second quintile & 0.89 & $0.51-1.53$ & 0.79 & $0.40-1.53$ \\
\hline Third quintile & 0.99 & $0.57-1.7$ & 1.27 & $0.64-2.49$ \\
\hline Fourth quintile & 1.28 & $0.73-2.26$ & 1.23 & $0.63-2.38$ \\
\hline Richest quintile & $3.85^{\mathrm{c}}$ & $1.99-7.43$ & $6.41^{c}$ & $3.07-13.38$ \\
\hline
\end{tabular}

and among the richer women compared to the poorer women.

\section{Discussion}

This research explored the secular trend of inequalities in Lao maternal health care services. Urban-rural disparity improved over time while there were no educational disparity changes. However, there were aggravation in the disparities between major and minor ethnic group as well as in the disparities between the rich and poor. The use of ANC and SBA services almost doubled from the year 2000 to 2012 in Lao PDR even though the utilization of these services were still low, compared to other MDG5 fast-track countries. About half of Lao women use ANC services while $89 \%$ in Cambodia, $88 \%$ in Vietnam, and 98\% in Rwanda utilize ANC. [23-26]. The rate of delivery assisted by skilled birth attendant in Lao PDR is $38 \%$ while it is $71 \%$ in Cambodia, $84 \%$ in Vietnam, and $69 \%$ in Rwanda [25].

This study has some limitations that should be noted. First, the data collected are from respondents' recall information, which was not validated with other objective data sources such as health facilities' ANC and SBA registration data. The validity of self-reported data constitutes some concerns in the literature. When the recall period is long, the mother might not remember all the events and activities she experienced, especially when she had several deliveries during the recall period. Second, the study relies on cross-sectional data with potential inconsistency between the questionnaires. The survey in 2000 did not collect information on postnatal care while the survey in 2012 had this information. As a result, the study could not assess all the three maternal health service utilization variables (antenatal, delivery, and postnatal care services). Therefore, the study focused only on two outcome variables: antenatal services and delivery with health professionals. The inconsistencies between the questionnaires also lead to the third limit of this study. We did not have enough information to control for other household and community factors that could influence the outcome variables such as marital status, husband's education, availability

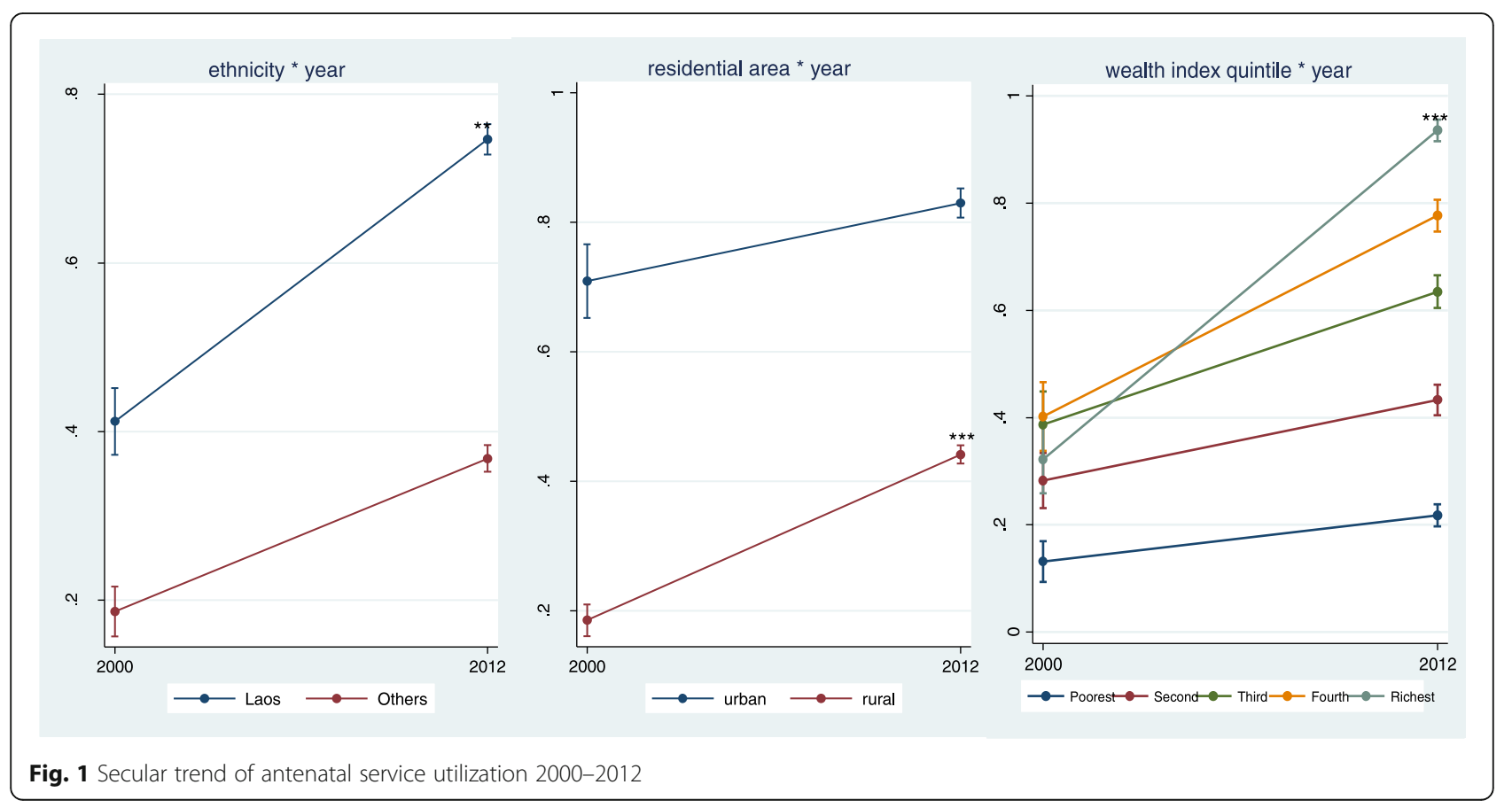




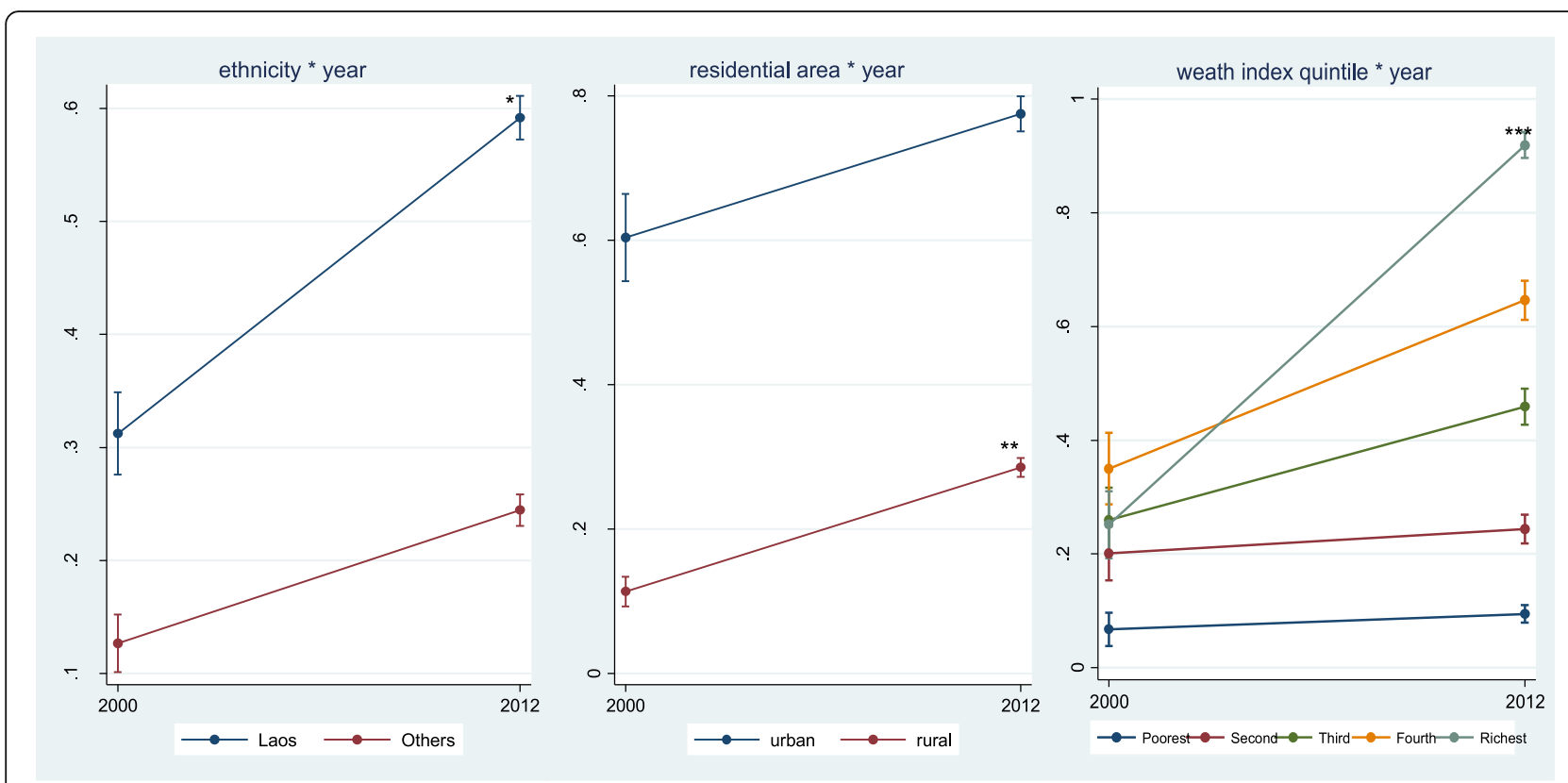

Fig. 2 Secular trend of delivery with health professionals 2000-2012

of maternal health services within the residential areas, and the distance from the women's house to the nearest health facilities.

Over the last decade, the number of women living in urban areas increased. The catch-up increase in using ANC is higher among women living in rural areas even though women living in urban areas are still using more services. This might be attributed to the interventions of the government and development partners as these programs have been focusing more on rural than urban areas. However, ethnic disparities in the use of services increased across ethnic groups. Lao ethnic women used more maternal health care services than non-Lao women. The increase in the use of services over time was higher among Lao ethnic women, increasing the gap between major and minor ethnic groups. This result may reflect the influence of culture on the maternal health care seeking behaviors. Many minor ethnicities in Lao PDR believe that the practice of child bearing is the responsibility of the mother herself and she should not receive any assistance from other people [27, 28]. Women with higher education are more likely to use maternal health services, it is unclear whether this trend is the same among non-Lao women. Although the exposure to media help increase the use of maternal health care services, over the last decade the media exposure rate decreased by $9 \%$. Such a decrease might be explained by the survey questions as the survey only asked the women about their exposure to radio, newspaper, and television and did not include the internet and social media. Therefore, further studies on the influence of education and media on the changes in maternal health care service seeking behavior are necessary, especially among minority ethnic groups and in rural areas.

\section{Conclusions}

Lao PDR has made dramatic progress over the last decade in reducing maternal mortality and became one of the 10 fast-track countries to achieve MDG 5. However, the utilization rate of maternal health care services should be improved to catch up with other fast-track countries. Moreover, the inequalities in utilizing maternal health care services across several different socioeconomic groups are also apparent. Therefore, in order to sustain the current progress and further reduce maternal mortality, the socioeconomic inequality issues should be addressed more aggressively. The improvement in disparities between rural and urban areas should go further for the most difficult remote areas in the high mountains where most minority people are living. Apart from health-related interventions, multi-sector participation, such as education and media, is needed to catch up with the socioeconomic changes and their effects on maternal health care services in Lao PDR.

\section{Additional file}

Additional file 1: Table S1. Summary of the variables used in the study. All the variables in the model of the study are summarized in this supplementary file. (DOCX $15 \mathrm{~kb}$ ) 


\section{Abbreviations}

ANC: Antenatal care; Cl: Confidence intervals; Lao PDR: Lao Peoples' Democratic Republic; MDG: Millennium Development Goal; MICS: Multiple Indicator Cluster Survey; OR: Odds ratio; SBA: Skilled birth attendant; UNICEF: United Nations International Children's Emergency Fund

\section{Acknowledgements}

The authors would like to acknowledge the Multiple Indicators Cluster Survey team of the UNICEF as well as the UNICEF Lao PDR country office for their support in providing the data.

\section{Availability of data and materials}

The datasets supporting the conclusion of this article are available at the website: http://mics.unicef.org/surveys

\section{Authors' contributions}

$\mathrm{ND}$ and $\mathrm{JO}$ conceived the study and designed the analysis model. ND analyzed the data and led the writing of the manuscript. JO, TTGH and AP provided critical inputs on the study approach as well as critical edits to the manuscript. All authors discussed the interpretation of the results and their implications. All authors read and approved the final manuscript.

\section{Ethics approval and consent to participate}

NA. We did not collect the data directly but used secondary data.

\section{Consent for publication}

Not applicable.

\section{Competing interests}

The authors declare that they have no competing interests.

\section{Publisher's Note}

Springer Nature remains neutral with regard to jurisdictional claims in published maps and institutional affiliations.

\section{Author details \\ ${ }^{1} \mathrm{JW}$ Lee Center for Global Medicine, Seoul National University College of Medicine, 71 Ihwajang-gil, Jongno-gu, Seoul 13087, Republic of Korea. 2Department of Global Health, Hanoi Medical University, Hanoi, Vietnam. ${ }^{3}$ Department of Economics and Business Management, Graduate Division, National University of Laos, Vientiane, Lao People's Democratic Republic.}

Received: 15 January 2018 Accepted: 6 July 2018

Published online: 13 July 2018

\section{References}

1. Zureick-Brown S, Newby H, Chou D, Mizoguchi N, Say L, Suzuki E, et al. Understanding global trends in maternal mortality. Int Perspect Sex Reprod Health. 2013;39:32-41.

2. Houweling TA, Ronsmans C, Campbell OM, Kunst AE. Huge poor-rich inequalities in maternity care: an international comparative study of maternity and child care in developing countries. Bull World Health Organ. 2007:85:745-54. https://doi.org/10.1590/s0042-96862007001000010.

3. Say $L$, Raine R. A systematic review of inequalities in the use of maternal health care in developing countries: examining the scale of the problem and the importance of context. Bull World Health Organ. 2007;85:812-9. https://doi.org/10.1590/s0042-96862007001000019.

4. Alam N, Hajizadeh M, Dumont A, Fournier P. Inequalities in maternal health care utilization in sub-Saharan African countries: a multiyear and multicountry analysis. PLoS One. 2015;10:e0120922. https://doi.org/10.1371/ journal.pone.0120922.

5. Mezmur M, Navaneetham K, Letamo G, Bariagaber H. Individual, household and contextual factors associated with skilled delivery care in Ethiopia: evidence from Ethiopian demographic and health surveys. PLoS One. 2017; 12:e0184688.

6. Ahmed S, Creanga AA, Gillespie DG, Tsui AO. Economic status, education and empowerment: implications for maternal health service utilization in developing countries. PLoS One. 2010;5:e11190. https://doi.org/10.1371/ journal.pone.0011190.
7. Babalola S, Fatusi A. Determinants of use of maternal health services in Nigeria-looking beyond individual and household factors. BMC Pregnancy Childbirth. 2009;9:43. https://doi.org/10.1186/1471-2393-9-43.

8. Hajizadeh M, Alam N, Nandi A. Social inequalities in the utili zation of maternal care in Bangladesh: have they widened or narrowed in recent years? Int J Equity Health. 2014;13:120. https://doi.org/10.1186/s12939014-0120-4

9. Hong R, Them R. Inequality in access to health Care in Cambodia. Asia Pacific J Public Heal. 2015;27:NP1039-49. https://doi.org/10.1177/ 1010539511428351.

10. Anwar I. Inequity in maternal health-care in Bangladesh. Bull World Health Organ. 2008;86 http://www.who.int/bulletin/volumes/86/4/07-042754.pdf. Accessed 4 Oct 2017

11. Bonfrer I, van de Poel E, Grimm M, Van Doorslaer E. Does the distribution of healthcare utilization match needs in Africa? Health Policy Plan. 2014;29: 921-37. https://doi.org/10.1093/heapol/czt074

12. Obiyan $\mathrm{MO}$, Kumar $\mathrm{A}$. Socioeconomic inequalities in the use of maternal health Care Services in Nigeria. Sage Open. 2015;5:215824401561407. https://doi.org/10.1177/2158244015614070.

13. Pathak PK, Singh A, Subramanian SV. Economic inequalities in maternal health care: prenatal care and skilled birth attendance in India, 1992-2006. PLoS One. 2010;5:e13593. https://doi.org/10.1371/journal.pone.0013593.

14. Boutayeb A, Helmert U. Social inequalities, regional disparities and health inequity in north African countries. Int J Equity Health. 2011;10:23. https:// doi.org/10.1186/1475-9276-10-23

15. McKinnon B, Harper S, Kaufman JS, Bergevin Y. Socioeconomic inequality in neonatal mortality in countries of low and middle income: a multicountry analysis. Lancet Glob Heal. 2014;2:e165-73. https://doi.org/10.1016/S2214109X(14)70008-7.

16. Zere E, Tumusiime P, Walker O, Kirigia J, Mwikisa C, Mbeeli T. Inequities in utilization of maternal health interventions in Namibia: implications for progress towards MDG 5 targets. Int J Equity Health. 2010;9:16. https://doi. org/10.1186/1475-9276-9-16

17. The Partnership for Maternal. Newborn \& Child Health In: The PMNCH 2013 progress report. Geneva, Switzerland: PMNCH; 2014. http://www. who.int/pmnch/knowledge/publications/progress_report2013.pdf. Accessed 3 Oct 2017

18. UNDP. MDGs Progress Report Lao PDR 2013 | UNDP in Lao PDR. 2014. http://www.la.undp.org/content/lao_pdr/en/home/library/mdg/mdgsprogress-report-lao-pdr-2013.html. Accessed 3 Oct 2017.

19. Health $M$ of. Health sector reform by 2020. Vientiane; 2013. chromeextension://oemmndcbldboiebfnladdacbdfmadadm/http://www. nationalplanningcycles.org/sites/default/files/planning_cycle_repository/lao_ peoples_democratic_republic/lao_hsr_strategy_and_framework_2025_ english_final_201702.pdf. Accessed 3 Oct 2017.

20. Vatcheva KP, Lee M, McCormick JB, Rahbar MH. The effect of ignoring statistical interactions in regression analyses conducted in epidemiologic studies: an example with survival analysis using cox proportional hazards regression model. Epidemiol (Sunnyvale). 2015;6:216. https://doi.org/10. 4172/2161-1165.1000216

21. Bauer DJ, Curran PJ. Probing interactions in fixed and multileve regression: inferential and graphical techniques. Multivariate Behav Res. 2005:40:373-400.

22. Ai C, Norton EC. Interaction terms in logit and probit models. Econ Lett. 2003:80:123-9.

23. Options Consultancy Services/Evidence for Action. Cambridge economic policy associates TP for MN. In: Success factors for Women's and Children's health: country specific review of data and literature on 10 fast-track countries' progress towards MDGs 4 and 5 an input to the country policy analyses and multistakeholder review meetings; 2013. http://www.who.int/pmnch/knowledge/publications/country_data_ review.pdf. Accessed 3 Oct 2017.

24. Dingle A, Powell-Jackson T, Goodman C. A decade of improvements in equity of access to reproductive and maternal health services in Cambodia, 2000-2010. Int J Equity Health. 2013;12:51. https://doi.org/10.1186/14759276-12-51.

25. Kuruvilla S, Schweitzer J, Bishai D, Chowdhury S, Caramani D, Frost L, et al. Success factors for reducing maternal and child mortality. Bull World Health Organ. 2014;92:533-44. https://doi.org/10.2471/BLT.14.138131.

26. World health statistics 2012. Geneva, Switzerland http://www.who.int/gho/ publications/world_health_statistics/EN_WHS2012_Full.pdf. Accessed 5 Oct 2017. 
27. King EM, Van De Walle D, Bank W. Laos: ethno-linguistic diversity and disadvantage. 2010. http://siteresources.worldbank.org/EDUCATION/ Resources/278200-1121703274255/1439264-1288632678541/75204521292532951964/Session2_Walle_Laos_Dec.20.pdf. Accessed 3 Oct 2017.

28. Ngan DK, Kang M, Lee C, Vanphanom S. "Back to basics" approach for improving maternal health care services utilization in Lao PDR. Asia Pacific J Public Heal. 2016;28:244-52. https://doi.org/10.1177/1010539516634188.

- fast, convenient online submission

- thorough peer review by experienced researchers in your field

- rapid publication on acceptance

- support for research data, including large and complex data types

- gold Open Access which fosters wider collaboration and increased citations

- maximum visibility for your research: over $100 \mathrm{M}$ website views per year 